\title{
Urban Oil Spill Management
}

\author{
James Li \\ Department of Civil Engineering \\ Ryerson University
}

\begin{abstract}
Urban oil spills occur frequently at industrial sites and along transportation corridors in North America. Although the cumulative spilled volume is large, there is limited research on how to manage these spills effectively. Under the Great Lakes Water Quality Agreement, Canada and United States have compiled urban spills and reported the trend since 1989. For instance, the Province of Ontario established a Spill Action Centre to collect and report spills in Ontario, and assist municipalities in spill responses. Since 1989, a database of more than 50,000 records has been compiled but no research was performed. Ryerson University research team has started urban spill research since 1998 and developed statistical and probabilistic models to facilitate urban spill management. The first stage of research focused on analyzing the characteristics of urban spills such as spill type, locations, volume, causes and reasons, impact media, and cleanup percentages. These characteristics were used to develop municipal oil spill prevention, control, and response plans. The current stage of research has developed spatial and temporal stochastic spill occurrence models which can be used to determine risk of future spills and management options. This presentation overviews the research applications in urban oil spill management.
\end{abstract}

